\title{
Influence of melatonin on pubertal development in male deer mice (Peromyscus maniculatus)
}

\author{
J. M. Whitsett, H. Underwood and J. Cherry \\ Department of Zoology, North Carolina State University, Raleigh, North Carolina 27650, U.S.A.
}

\begin{abstract}
Summary. The role of melatonin in pubertal development was assessed in male deer mice (Peromyscus maniculatus bairdii) exposed to photoperiodic and social stimuli. Exogenous melatonin retarded puberty in males reared in a long photoperiod, but was without effect in males reared in short days. Melatonin did not retard pubertal development induced by exposure of short-day males to an adult female. These results suggest that pineal melatonin mediates photoperiodic, but not social, control of pubertal development.
\end{abstract}

\section{Introduction}

The pineal hormone melatonin appears to mediate the photoperiodic regulation of seasonal breeding cycles in adults of several species of mammals. In long-day breeders, removal of the pineal gland usually blocks the inhibition of reproductive function resulting from exposure to short photoperiods (Hoffman \& Reiter, 1965; Farrar \& Clarke, 1976; Petterborg, Reiter \& Brainard, 1981). In addition, exogenous administration of melatonin tends to inhibit reproduction in individuals exposed to long days (Rust \& Meyer, 1969; Lynch \& Epstein, 1976; Johnston \& Zucker, 1980; Dark, Johnston, Healy \& Zucker, 1983). Such data suggest that increased, or otherwise altered, secretion of melatonin by the pineal organ is responsible for termination of the reproductive season in long-day breeders.

The pineal system may also play a role in the regulation of pubertal development in mammals. Pinealectomy counters the short-day-induced inhibition of puberty in Djungarian hamsters (Brackmann \& Hoffmann, 1977) and white-footed mice (Johnston, Boshes \& Zucker, 1982), and, in both species, subcutaneous implants of melatonin inhibit pubertal development in individuals reared in long days (Brackmann, 1977; Petterborg \& Reiter, 1980).

Prairie deer mice (Peromyscus maniculatus), congeneric to white-footed mice ( $P$. leucopus), have proved to be excellent subjects for studies of the environmental regulation of reproductive development, because their development is influenced by at least two classes of stimuli in the external environment: photoperiod and social cues. Pubertal development in male and female deer mice is relatively rapid when they are reared in long photoperiods and relatively slow under the influence of a short-day regimen (Whitsett \& Lawton, 1982; Whitsett \& Miller, 1982). Puberty in young males is retarded when they are reared in the presence of an adult male (Bediz \& Whitsett, 1979); similarly, exposure of young females to adult females retards puberty (Garcia \& Whitsett, 1983). The presence of adult males stimulates puberty in females (Garcia \& Whitsett, 1983), and cohabitation with adult females stimulates development in young males that otherwise would be inhibited by exposure to a short photoperiod (Whitsett \& Lawton, 1982). The present report describes a series of 3 experiments to investigate the possible role of melatonin in the photoperiodic and social regulation of pubertal development in male deer mice. 


\section{General Methods}

Care and breeding of the prairie deer mice (Peromyscus maniculatus bairdii) were as described previously (Whitsett, Lawton \& Miller, 1984a), except where noted.

Males were weaned and assigned to treatment groups at 3 weeks of age. Silastic capsules, $10 \mathrm{~mm}$ long (Dow Corning, Midland, MI; cat. no. 602-235), were filled with $\sim 5 \mathrm{mg}$ crystalline melatonin (Sigma Chemical Co., St Louis, MO) and sealed at both ends. Control capsules were prepared similarly, but left empty. Under ether anaesthesia, a capsule was placed beneath the skin of a weanling male through an incision in the nape of the neck. The males were killed at 6 weeks of age, and were frozen at $-20^{\circ} \mathrm{C}$ for later measurement of reproductive organs and body weight.

Because reproductive organ weight and body weight were positively correlated, the contribution of body weight to variance in organ weight was removed by analysis of covariance. Results have been summarized as least squares means, adjusted for differences in body weight, and differences in these adjusted means were tested using the General Linear Models procedure of the Statistical Analysis System (SAS Institute Inc., 1982).

\section{Detailed Methods and Results}

\section{Experiment 1}

Female breeders were exposed to a lighting regimen of $15 \mathrm{~h}$ light: $9 \mathrm{~h}$ dark $(15 \mathrm{~L}: 9 \mathrm{D})$ during the period of mating, pregnancy and lactation. Male offspring were weaned at 21 days of age and were, on a random basis, implanted with a single capsule of melatonin $(\mathrm{N}=18)$ or left unoperated as a control group $(\mathrm{N}=21)$. The males were housed individually until 42 days of age when they were killed for determination of reproductive condition.

Males given implants of melatonin had smaller seminal vesicles than did control (unimplanted) mice $(33.4 \pm 9.1$ compared with $64.4 \pm 8.4 \mathrm{mg}$, respectively; $F(1,36)=6.09, P<0.02)$. Although in the same direction, the difference in testis weights $(159 \cdot 7 \pm 31 \cdot 1$ and $191 \cdot 1 \pm 12 \cdot 1 \mathrm{mg})$ was not statistically significant $[F(1,36)=3.03, P>0.05]$. Body weight was not influenced by melatonin treatment $(15.8 \pm 0.5 \mathrm{~g}$ compared with $16.6 \pm 0.3 \mathrm{~g}$ in controls: $F(1,37)=1.60, P>0.05)$, but it was positively correlated with both testis weight $(r=0.49)$ and seminal vesicle weight $(r=0 \cdot 35)$.

\section{Experiment 2}

Because the degree of inhibition in males receiving melatonin implants in Exp. 1 was not as great as that usually observed in male deer mice reared under conditions of a short photoperiod (Whitsett et al., 1984a; Whitsett, Noden, Cherry \& Lawton, 1984b), in Exp. 2 a short-day control group was compared with groups receiving different doses of melatonin.

Female breeders, previously housed in a long photoperiod were exposed to a lighting regimen of $6 \mathrm{~L}: 18 \mathrm{D}$ beginning at the time of mating and continuing through the period of lactation. Male offspring were weaned at 21-22 days of age and randomly assigned to 1 of 5 treatment conditions : long photoperiod (16L:8D) plus $0,1,2$ or 3 capsules of melatonin or short photoperiod $(6 \mathrm{~L}: 18 \mathrm{D})$ without melatonin. Individuals not receiving melatonin-filled capsules were implanted with empty capsules. The deer mice were killed at 45-46 days of age for measurement of reproductive condition.

Melatonin implants inhibited reproductive development. $F$ tests based on a completely randomized experimental design indicated an overall treatment effect for both testis weight $(F(4,59)=5 \cdot 73, P<0.001)$ and seminal vesicle weight $(F(4,59)=5 \cdot 10, P<0.002)$. There was, however, no differential effect of dosage of melatonin. A single capsule of melatonin inhibited reproductive development in males housed in a long photoperiod as effectively as did exposure of males to short days. Dose groups have therefore been combined for presentation of least squares 


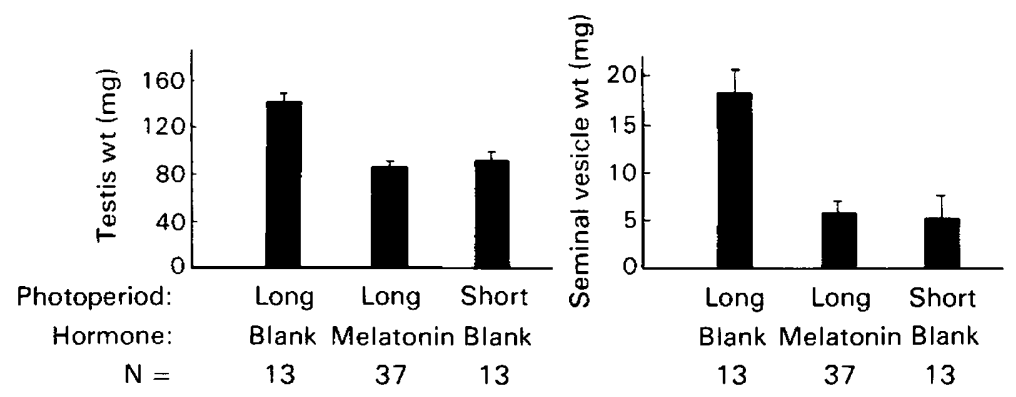

Text-fig. 1. Influence of photoperiod and melatonin treatment on reproductive organ size in male deer mice at 6 weeks of age in Exp. 2. Data expressed as least squares mean (adjusted for body weight) plus standard error.

means in Text-fig. 1. Exposure to a short photoperiod inhibited development of testes and seminal vesicles. Body weight was not affected by the treatments $(F(4,61),<1)$, but was correlated with testis weight $(r=0.66)$ and seminal vesicle weight $(r=0.33)$.

\section{Experiment 3}

Male deer mice, housed in a lighting regimen of $6 \mathrm{~L}: 18 \mathrm{D}$ until weaning, received implants of a single $10 \mathrm{~mm}$ capsule containing melatonin or an empty capsule. In addition, they were assigned to
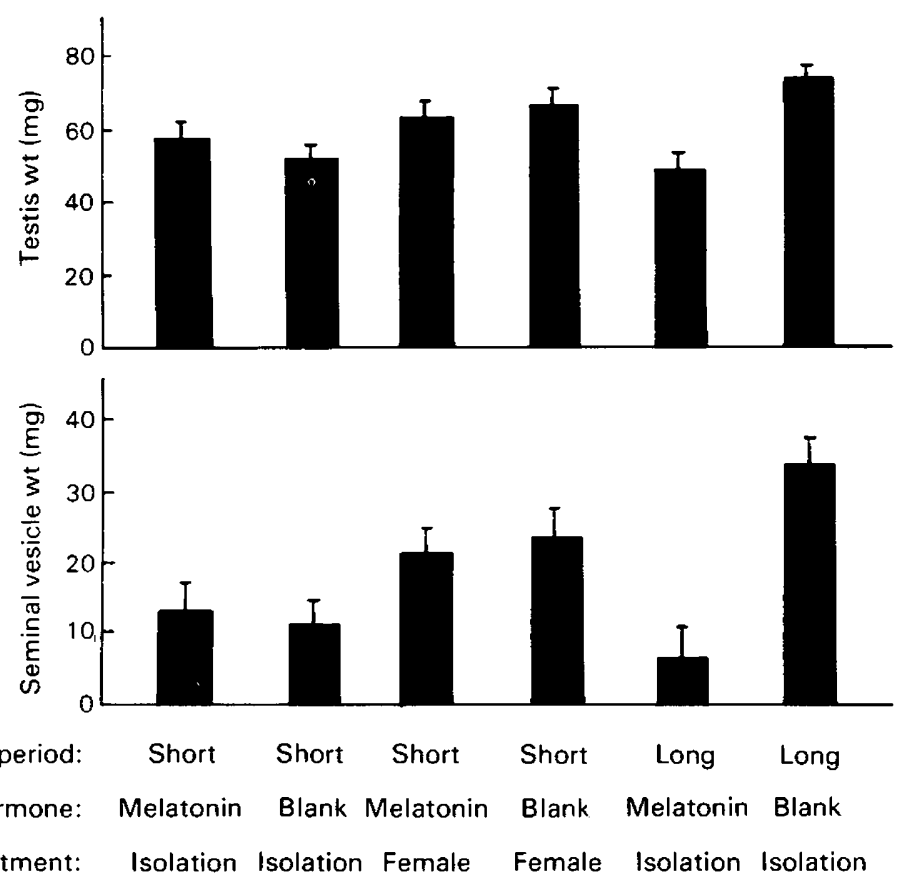

Text-fig. 2. Influence of photoperiod, presence of adult female, and melatonin treatment on testicular and seminal vesicle size in male deer mice at 6 weeks of age in Exp. 3. Data expressed as least squares mean (adjusted for body weight) plus standard error. Sample size $=20$ individuals per treatment condition. 
Table 1. Analysis of variance source table for test of influence of melatonin administration and social and photoperiodic treatment on reproductive organ size in male deer mice at 6 weeks of age in Exp. 3

\begin{tabular}{|c|c|c|c|c|c|c|}
\hline & \multicolumn{3}{|c|}{ Testis wt } & \multicolumn{3}{|c|}{ Seminal vesicle wt } \\
\hline & $\mathrm{df}$ & MS & Significance* & $\mathrm{df}$ & MS & Significance \\
\hline Hormone & 1 & 1563 & NS & 1 & 2402 & $P<0.01$ \\
\hline Environment & 2 & - & - & 2 & - & - \\
\hline Social $\uparrow$ & 1 & 1865 & $P<0.05$ & 1 & 2005 & $P<0.01$ \\
\hline Photoperiod $\dagger$ & 1 & 20 & NS & 1 & 182 & NS \\
\hline Hormone $\times$ Environment & 2 & - & - & 2 & - & - \\
\hline Hormone $\times$ Social & 1 & 427 & NS & 1 & 83 & NS \\
\hline Hormone $\times$ Photoperiod & 1 & 4754 & $P<0.001$ & 1 & 4601 & $P<0.001$ \\
\hline Error & 113 & 473 & -- & 113 & 287 & - \\
\hline
\end{tabular}

MS $=$ mean square; NS $=$ not significant.

* Probability associated with F ratio of treatment MS :error MS.

† Orthogonal comparisons: short-day isolated males versus short-day with female, long day versus all short-day groups.

1 of 3 environmental treatments: (a) long photoperiod (16L:8D) combined with rearing in social isolation, (b) short photoperiod (6L:18D) and social isolation, or (c) short days $(6 \mathrm{~L}: 18 \mathrm{D})$ and continuous cohabitation with an adult female. Thus the experiment was based on a $2 \times 3$ factorial design, with 2 levels of hormonal treatment and 3 levels of environmental treatment. Weanlings were assigned to the 6 treatment groups on a random basis. The experiment was terminated at 6 weeks of age for measurement of reproductive organs. Release rates for melatonin were estimated by weighing capsules before and after the experiment. Assuming a constant rate over the 3 weeks of implantation, an individual was exposed to approximately $12 \mu \mathrm{g}$ melatonin/10-mm capsule/day. Although based on a crude procedure, this figure is comparable to estimates in similar studies (Turek, Desjardins \& Menaker, 1976).

Exogenous melatonin treatment inhibited pubertal development in male deer mice exposed to the stimulatory influence of a long photoperiod, but not in those stimulated by the presence of a female (Text-fig. 2). The data were analysed by analysis of covariance in accordance with the partitioning of sums of squares indicated in Table 1. Because of the complexity of the experimental design, specific orthogonal contrasts and associated interactions, rather than main effects, are of primary interest. As shown in Table 1, cohabitation with an adult female stimulated the development of testes and seminal vesicles in males reared in a short photoperiod. The statistically significant 'hormone $\times$ photoperiod' interaction signifies a melatonin-induced reduction in organ development in long-day, but not in short-day, males. The lack of a significant 'hormone $\times$ social environment' interaction reflects the lack of influence of melatonin on development in short-day males housed in social isolation or in cohabitation with a female.

\section{Discussion}

In males reared in a long photoperiod, the presence of a subcutaneous capsule containing melatonin inhibited reproductive development, as measured by weights of reproductive organs at 6 weeks of age. Although a single capsule of melatonin appeared to be only partly effective in inhibiting maturation in Exp. 1, the dose-response investigation in Exp. 2 indicated full effectiveness, relative to the inhibitory influence of a short photoperiod, of a single capsule containing $\sim 5 \mathrm{mg}$ melatonin. Again in Exp. 3, the single melatonin implant inhibited development in long-day males as effectively as did exposure of other individuals to a short photoperiod. 
Chronic implants of melatonin retard testicular development in white-footed mice reared in a long photoperiod (Petterborg \& Reiter, 1980); seminiferous tubule diameter was reduced and spermatogenesis was incomplete when the mice were examined at 6 weeks of age, 3 weeks after implantation of pellets of melatonin embedded in beeswax. Melatonin implants also inhibit puberty in young Djungarian hamsters and do so in a dose-related manner (Brackmann, 1977). Melatonin-induced inhibition of maturation is seen in pinealectomized and sham-operated Djungarian hamsters (Hoffmann \& Küderling, 1977), indicating that the presence of the pineal gland is not necessarily required for the anti-gonadal influence of exogenous melatonin. Thus, evidence from 3 species, including the deer mouse, suggests that pineal melatonin mediates the photoperiodic control of pubertal development and does so, at least in part, by exerting an inhibitory influence.

In addition to its well described inhibitory influence on reproduction, melatonin can also stimulate the reproductive system in certain circumstances. This "progonadal" (Turek et al., 1975) or "counterantigonadotropic" (Reiter, 1980) influence has been described most frequently for hamsters. In a study of Djungarian hamsters held under natural illumination before use in experiments, the response to melatonin treatment varied with season of the year, yielding results ranging from anti-gonadal to ineffective to pro-gonadal (Hoffmann, 1981). Hoffmann (1981) has argued that chronic availability of melatonin acts against the influence of the prevailing photoperiod. The direction and magnitude of the influence of exogenous melatonin treatment on reproductive function in golden hamsters appear to depend on an extraordinary variety of physiological, environmental and methodological factors (Reiter, 1980).

Exposure of male deer mice to a short photoperiod inhibited reproductive development (Exps 2 and 3), and the presence of melatonin implants did not alter the response to short days (Exp. 3). We therefore find no support for the notion that melatonin can exert a pro-gonadal influence on pubertal development in deer mice, although different experimental paradigms might of course produce such a result.

Exposure to adult females stimulates pubertal development in young male deer mice. Previous data (Whitsett \& Lawton, 1982) and the results of Exp. 3 of the present study suggest that a female is a less potent stimulus to male development than is a long photoperiod. These are, however, quite disparate stimuli and other experimental procedures might well erase this apparent difference in potency. For example, the use of a slightly shorter photoperiod (Whitsett et al., 1984b) combined with daily replacement of females might increase the effectiveness of females relative to photoperiodic stimulation. In female deer mice, continuous exposure to a single adult male appears to be as effective as exposure to a 15 -h photoperiod in stimulating pubertal development (Garcia \& Whitsett, 1983).

As yet, there is little direct evidence regarding the role of the pineal system in the regulation of reproduction by environmental factors other than photoperiod. A small amount of circumstantial evidence suggests pineal involvement in social influences on reproduction. Blinding of an adult rat has no influence on its reproductive condition; blinding of a young rat produces a slight, but significant, retardation of its reproductive development. Rats that are both blind and anosmic exhibit a dramatic gonadal regression or inhibition of development, in adults and young, respectively; pinealectomy completely reverses this gonadal inhibition (Reiter, Klein \& Donofrio, 1969; Reiter et al., 1971; Chen \& Reiter, 1980). Perhaps in the rat, as well as in the deer mouse, both photic and social olfactory cues regulate reproduction, although greater experimental contrivance is required to see their joint influence in the rat. The reversal of this influence by removal of the pineal gland certainly implicates this organ as a possible mediator of the synergistic effect of the two types of sensory input in the rat, even though Reiter et al. (1969) regard the pineal enzymic activity data as inconsistent with this view. A link between the olfactory system and the habenulopineal complex has also been postulated on the basis of physiological and anatomical evidence (Miline, Devecerski \& Krstic, 1963).

Experiment 3 was an initial attempt to evaluate the possible role of the pineal system in the 
social regulation of pubertal development in deer mice. We determined whether administration of melatonin, in a dosage sufficient to block maturation in males reared in a long photoperiod, would nullify the stimulatory influence of exposure to an adult female in males reared in short days. The results indicated that melatonin had no effect on males developing under the influence of female stimulation. This finding constitutes preliminary evidence of a lack of involvement of the pineal gland in the mediation of social influences on pubertal development. Clearly, pineal substances other than melatonin, such as polypeptides, could be involved in mediating the effects of olfactory stimuli. The effect of pinealectomy on the inhibition of maturation in response to intra-sexual social cues needs to be assessed before a role for the pineal in mediating social influences on reproductive development can be dismissed.

This investigation was supported in part by U.S. Environmental Protection Agency Grant CR809428010 and National Science Foundation Grant PCM8116880. H.U. is the recipient of Research Career Development Award 5K04 HD00276-02 from the National Institute of Child Health and Human Development.

\section{References}

Bediz, G.M. \& Whitsett, J.M. (1979) Social inhibition of sexual maturation in male prairie deer mice. $J$. comp. Physiol. Psychol. 93, 493-500.

Brackmann, M. (1977) Melatonin delays puberty in the Djungarian hamster. Naturwissenschaften 64, 642643.

Brackmann, M. \& Hoffmann, K. (1977) Pinealectomy and photoperiod influence testicular development in the Djungarian hamster. Naturwissenschaften 64, $341-342$.

Chen, H.J. \& Reiter, R.J. (1980) Influence of subcutaneous deposits of melatonin on the antigonadotrophic effects of blinding and anosmia in male rats: a doseresponse study. Neuroendocrinology 30, 169-173.

Dark, J., Johnston, P.G., Healy, M. \& Zucker, I. (1983) Latitude of origin influences photoperiodic control of reproduction of deer mice (Peromyscus maniculatus). Biol. Reprod. 28, 213-220.

Farrar, G.M. \& Clarke, J.R. (1976) Effect of chemical sympathectomy and pinealectomy upon gonads of voles (Microtus agrestis) exposed to short photoperiod. Neuroendocrinology 22, 134-143.

Garcia, I.M.P.S. \& Whitsett, J.M. (1983) Influence of photoperiod and social environment on sexual maturation in female deer mice (Peromyscus maniculatus bairdii). J. comp. Psychol. 97, 127-134.

Hoffman, R.A. \& Reiter, R.J. (1965) Pineal gland: influence on gonads of male hamsters. Science, N.Y. 148, 1609-1611

Hoffmann, K. (1981) The role of the pineal gland in the photoperiodic control of seasonal cycles in hamsters. In Biological Clocks in Seasonal Reproductive Cycles, pp. 237-250. Eds B. K. Follett \& D. E. Follett. Wright, Bristol.

Hoffmann, K. \& Küderling, I. (1977) Antigonadal effects of melatonin in pinealectomized Djungarian hamsters. Naturwissenschaften 64, 339-340.

Johnston, P.G. \& Zucker, I. (1980) Antigonadal effects of melatonin in white-footed mice (Peromyscus leucopus). Biol. Reprod. 23, 1069-1074.

Johnston, P.G., Boshes, M. \& Zucker, I. (1982) Photoperiodic inhibition of testicular development is mediated by the pineal gland in white-footed mice. Biol. Reprod. 26, 597-602.

Lynch, G.R. \& Epstein, A.L. (1976) Melatonin induced changes in gonads, pelage and thermogenic characters in the white-footed mouse, Peromyscus leucopus. Comp. Biochem. Physiol. 53C, 67-68.

Miline, R., Devecerski, V. \& Krstic, R. (1963) Influence d'excitations olfactives sur le systeme habenuloepiphysaire. Annls Endocr. 24, 377-379.

Petterborg, L.J. \& Reiter, R.J. (1980) Effect of photoperiod and melatonin on testicular development in the white-footed mouse, Peromyscus leucopus. $J$. Reprod. Fert. 60, 209-212.

Petterborg, L.J., Reiter, R.J. \& Brainard, G.C. (1981) Ovarian response of pinealectomized and intact white-footed mice kept under naturally short photoperiods. Experientia 37, 247.

Reiter, R.J. (1980) The pineal and its hormones in the control of reproduction in mammals. Endocrine Rev. 1, 109-131.

Reiter, R.J., Klein, D.C. \& Donofrio, R.J. (1969) Preliminary observations on the reproductive effects of the pineal gland in blinded, anosmic male rats. $J$. Reprod. Fert. 19, 563-565.

Reiter, R.J., Sorrentino, S., Jr, Ralph, C.L., Lynch, H.J., Mull, D. \& Jarrow, E. (1971) Some endocrine effects of blinding and anosmia in adult male rats with observations on pineal melatonin. Endocrinology 88, 895-900.

Rust, C.C. \& Meyer, R.K. (1969) Hair color, molt, and testis size in male, short-tailed weasels treated with melatonin. Science, N.Y. 165, 921-922.

SAS Institute Inc. (1982) SAS User's Guide: Statistics, 1982 edn. SAS Institute, Inc., Cary, NC.

Turek, F.W., Desjardins, C. \& Menaker, M. (1975) Melatonin: antigonadal and progonadal effects in male golden hamsters. Science, N.Y. 190, 280-282.

Turek, F.W., Desjardins, C. \& Menaker, M. (1976) Melatonin-induced inhibition of testicular function in adult golden hamsters. Proc. Soc. exp. Biol. Med. 151, 502-506.

Whitsett, J.M. \& Lawton, A.D. (1982) Social stimulation 
of reproductive development in male deer mice housed on a short-day photoperiod. J. comp. Physiol. Psychol. 96, 416-422.

Whitsett, J.M. \& Miller, L.L. (1982) Photoperiod and reproduction in female deer mice. Biol. Reprod. 26, 296-304.

Whitesett, J.M., Lawton, A.D. \& Miller, L.L. (1984a) Photosensitive stages in pubertal development of male deer mice (Peromyscus maniculatus). J. Reprod. Fert. 72, 269-276.
Whitsett, J.M., Noden, P.F., Cherry, J. \& Lawton, A.D. (1984b) Effect of transitional photoperiods on testicular development and puberty in male deer mice (Peromyscus maniculatus). J. Reprod. Fert. 72, 277286.

Received 21 November 1983 